\title{
A Role of cryogenic in Wire cut EDM process
}

\author{
Kosaraju Satynarayana ${ }^{1, *}$, Kumkuma Rajkiran $^{2}$, Pujari Anil kumar ${ }^{3}$, D Chakradhar ${ }^{4}$ \\ ${ }^{1}$ Assoc.Professor, GRIET, Mechanical Engineering Department, Bachupally 500090, Hyderabad, India. \\ ${ }^{2}$ PG Student GRIET, Mechanical Engineering Department, Bachupally 500090, Hyderabad, India. \\ ${ }^{3}$ Senior Design Enginer, Invilogic software Pvt.Ltd, Madhapur 500081, Hyderabad, India \\ ${ }^{4}$ Assi.Professor, IIT Palakkad, Kozhippara 678557, Kerala, India
}

\begin{abstract}
Novel techniques are being focused on the enrichment of the performance characteristics under different machining processes. Cryogenic is one of such novel practices that tunes the surface integrity with vast variations with the traditional machining processes. Dimensional accuracy, surface roughness, material removal rate with less reduction in scrap of material is one of the prior targets of production process. Wire cut Electro Discharge Machining (WEDM) is one method that satisfy with upgrading performance characteristics. In order to step-up these performance characteristics in attaining superior quality, cryogenics practices have collaborated with the WEDM process. Present paper deals with the reviews of the researchers that have been performed over cryogenic treated WEDM process. Effect of performance characteristics like pulse on, pulse off, current, voltage, wire tension, wire feed is discussed with relation to material removal rate, tool wear rate and surface roughness evolved. Key concept of paper is to include the research ideology with best feasible techniques that can prevail in production practice in order of contribute to the forthcoming researches in industrial and production departments.
\end{abstract}

\section{Introduction}

Wire cut electro-discharge is one of the non-traditional process in which the workpiece with machined without any direct contact of tool to the workpiece. As the machining term WEDM titled, process is done purely with the discharge of electrons with in the tool (wire) and workpiece. Work piece and tool wire acts as the conductor barriers for which the emulsion of sparks takes place at contact area. At the contact zone of wire to metal, sparks are produced which further proceeds in erosion to workpiece. With this key principle methodology the machining is done.

The process of erosion using electrons was first presented by Joseph Priestley, a physicist in early 1770 . Then it lead the ideas of developing the energy of erosion further after few centuries there was successive result carried out by B.R lanzarenko and N.I lazarenko for best use of erosion in machining process. The invention of R-C-type machine by these Russian scientists took a major step in machining hard-to-cut materials [31] with basic erosion principle. The process of machining was manualized till 1970 and after the end of 1970's the process of erosion was controlled by numerical controlled systems (NC). Then after in the upgrading process D.H Duebohn introduced the process of optial line follower process in 1974 by which the rate of accuracy of the products increased. WEDM or EDM process where only designed in fabrication of tools, dies, jigs which need a high accuracy without the consideration of hardness of materials. Present available machines are products of these upgraded techniques. For further improvement of the machinability cryogenic techniques is introduces in the field of EDM

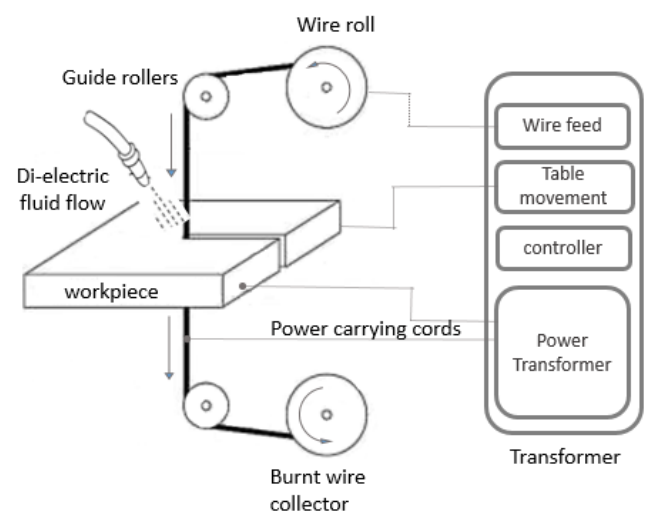

Fig 1 line diagram of wire cut EDM process.

Cryogenics is the process of investigation of materials and their qualities at a very low temperature. Cryogenics is a Greek word which means cryo "cold" and - genic "production" cryogenic has a wide range of applications in the fields of mechanical, medical, aeronautical, automotive industries as of their low temperature with stand property. Cryogenic fluids are usually termed to the liquid stage of gases with are found to be under$150^{\circ} \mathrm{c}$ they usually exits in the stage slightly toxic with or without odour and colour. As mentioned they are used in

\footnotetext{
* Corresponding author: author@e-mail.org
} 
the fields of mechanical machining for their good performance while machining operations. They increase the hardness of materials with making it homogenous. These factors supports in increasing of tool life and machinability properties of metals. Cryogenics is usually performed while machining the hard-to-cut metals mostly super alloys.

Usage of cryogenic fluids are termed to be a unconventional process of machining which eliminate effects on human health as well as on environment. [1]. It was initially used to harden the tool in 1940's. cryogenic treatments are used in various mechanical machining processes such as in Drilling [2], Milling [3], Bending [4], Tool hardening [5], forming and grinding [6], Turning [7].

Table 1. Cryogenic fluids, its temperature and availability in nature

\begin{tabular}{|l|l|l|l|}
\hline Cryogenic fluid & Centigrade & Nature & Avl. In Nature \\
\hline Helium 3 & -269.96 & Inert gas & $5 \mathrm{ppm}$ \\
\hline Helium 4 & -268.94 & Inert gas & $5 \mathrm{ppm}$ \\
\hline Hydrogen & -252.88 & Combustible & $0.6 \mathrm{ppm}$ \\
\hline Neon & -246.06 & Neutral & $18 \mathrm{ppm}$ \\
\hline Nitrogen & -196.06 & Neutral & $78.09 \%$ \\
\hline Mixture of air & -194.35 & Neutral & $100 \%$ \\
\hline Fluorine & -187.91 & Toxic & $0.6 \mathrm{ppb}$ \\
\hline Argon & -185.91 & Inert gas & $0.94 \%$ \\
\hline Oxygen & -182.97 & Flammable & $20.95 \%$ \\
\hline Methane & -161.45 & Flammable & $1866 \mathrm{ppb}$ \\
\hline Carbon dioxide & -56.6 & Neutral & $0.04 \%$ \\
\hline
\end{tabular}

Cryogenics treatment of electrodes enhance the wire quality in terms of wear and conductivity [8]. Cryogenic treatment is done in two methods. Deep cryogenic treatment ad shallow cryogenic treatment.[9].liquid nitrogen is mostly used as the fluid for the cryogenic treatment of metals. Cryogenic treatment can also be done without tempering the metal [10].

\section{WEDM machining parameters their Effect}

There are various parameters in wirecut EDM process like current, voltage, pulse on-time, pulse off-time, wire material wire feed rate, wire tension and dielectric fluid. In the following section effect of these parameters are discussed. The following figure-2 represents the schematic flow chart of the parameters and their contribution of effect of performance characteristics.

Pulse duration, current, type of electrode wire are the factors that contributes to the surface roughness, whereas pulse off time voltage and wire feed rate tunes the material removal rate.

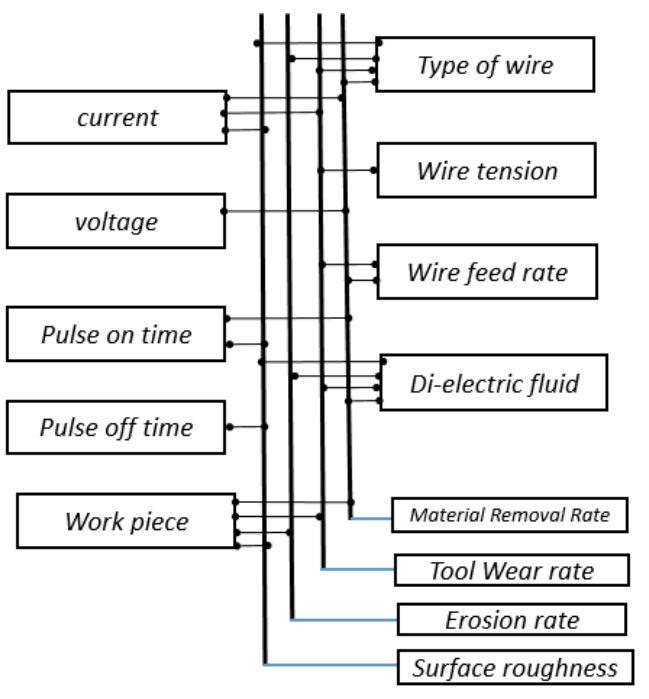

Fig 2. Input effects over performance in WEDM.

\subsection{Current $\left(I_{p}\right)$}

It is the power that is supplied to the WEDM machine. This current is used during the pulse time for actual machining process. It is measured in the terms of ampere (A). Current is the factor that deals with the surface roughness and material removal rate. The higher the ampere the larger the material erosion leading to high surface roughness. Ampere is not based on the strength of material but on the conductivity and machining process [11].

\subsection{Voltage (v)}

Voltage in the WEDM process is categorised in two forms. Servo voltage (SV) and gap voltage (GV). The voltage that advances the wire movement terms to be servo voltage. Servo voltage (SV) is regulated by the pulse timing rate and contributes with tool wear rate. Whereas the voltage that plays a actual role in formation of spark between the wire and workpiece is termed as the gap voltage. The higher the voltage rate the higher the erosion rate. Gap voltage enhance the machinability of wire as it causes the low wear and even cut off the wire during the process [11].

\subsection{Pulse on time $\left(T_{o n}\right)$}

Pulse refers to the spark or erosion in WEDM whereas pulse time deals with the duration of spark produced between the wire and workpiece. Pulse on time refers to the time that spark has been active and performed the erosion of on the workpiece. Time duration is tuned in microseconds, more the duration of pulse the more the spark production and the more heat generated and material removal rate [12]. It is measured in micro seconds. 


\subsection{Pulse off time $\left(T_{\text {off }}\right)$}

Time between two consecutive sparks is referred as pulse off time. It is pause of microseconds for the spark and wire rotation. As it is in micro-seconds, the distraction in wire flow and sparks is not noticed while machining. Pulse off time is taken as a factor as this micro-seconds gives up chance in cooling the work zone and remove the brunt out of debits of previous erosion. $\mathrm{T}_{\text {off }}$ should be in sequence to the Ton to reduce the over power load on the transformer, which further leads to wire breakage [13]. The lower the $\mathrm{T}_{\text {off }}$ the higher the machining time and more MRR

\subsection{Wire material}

Selection of wire is one of the important term to be considered and to be literate as per the machining parameters. Conductivity, strength, uniformity, purity, tensile strength, surface integrity and melting points are key points that are to be taken into factor in selection of wire. Pure wires are used in majority of WEDM process in order to obtain good conductivity. Pure copper [14], pure brass [15], pure tungsten [16]. Researchers have found that pure wires are poor to with stand high temperature. They also cause the carbon deposited over them which form a thin layer of induced carbon layer. To overcome this effect use of coated wire electrodes advanced the machinability of WEDM [17]. A clear structure of types of wires, conductivity and properties have been stated in review over wire electrodes by Ibrahim [18].

\subsection{Wire feed rate $\left(W_{f}\right)$}

Wire federate is mentioned as the flow rate and retraction of wire during the machining process. The higher the feed rate, the low the tool wear rate, and more the surface finish. Feed rates tunes the production cost leading to product cost. Feed rate is calculated at $\mathrm{mm} / \mathrm{min}$ flow rate.

\subsection{Wire tension $\left(W_{t}\right)$}

Accuracy is prior factor that is expected in the WEDM process. Accuracy in terms of dimension and linearity. To obtain this factor, wire is to be maintained in straight line axis. For this cause wire is loaded with a basic minimum load by the guide rollers. Spark produces a ultrasonic vibration on workpiece and wire. Workpiece is arrested by fixture and in order to arrest the arrest the wire tension is added to it. Higher wire tension causes the wire breakage and wire elongation which further turns to breakage or lag. Usually the tension on wire is applied at a rate of 0.3 to $10 \mathrm{~N}$.

\subsection{Di-electric fluid}

Di-electric fluid is the liquid that is flowed over the erosion zone. This accords in reduction of heat and removal of debris form the zone. Di-electric fluid is circulated in the collection tank. Cleanliness, clear, nontoxic, pure, odourless, transparent, non-corrosive, nonreactive, low evaporate are the key concepts in selection of di-electric fluid. De-ionized water [19] kerosene [20].

\section{Cryogenic treated wires}

Cryogenic treatment is done in form of ramp down and ramp up which denotes $\mathrm{s}$ temperature cooled from room temperature to sub-zero is called as ramp down and temperature raising from sub-zero id called as ramp up. Usually these processes are don't in controlled conditions such as $10 \mathrm{c} / \mathrm{min}$ or so on. This process takes in perfect equilibrium static condition to facilitate good grain structure. Sudden cooling or sudden heating then causes cracks, internal defects and also sudden breakage of the material.

Cryogenic treatment is done in form of ramp down and ramp up which denotes $\mathrm{s}$ temperature cooled from room temperature to sub-zero [34] is called as ramp down and temperature raising from sub-zero id called as ramp up. Usually these processes are don't in controlled conditions such as $1^{0} \mathrm{c} / \mathrm{min}$ or so on. This process takes in perfect equilibrium static condition to facilitate good grain structure. Sudden cooling or sudden heating then causes cracks, internal defects and also sudden breakage of the material. Treated electrode had decreased with $51 \%$ in TWR, 39\% in MRR and increased with $4.5 \%$ in electric conductivity [25].

\subsection{Copper wire}

Pure copper has tendency of high ductility and low tensile strength. Additives to copper ads up the strength and there by decreases the conductivity. On order to attain high tensile strength with no change can be achieved by cryogenic treatment. Authors [21, 22] has proved to find out the good surface finish in using pure copper wire. Cryogenic treated copper electrode had decreased with $35 \%$ in TWR, 34\% in MRR and increased with $10 \%$ in electric conductivity [25].

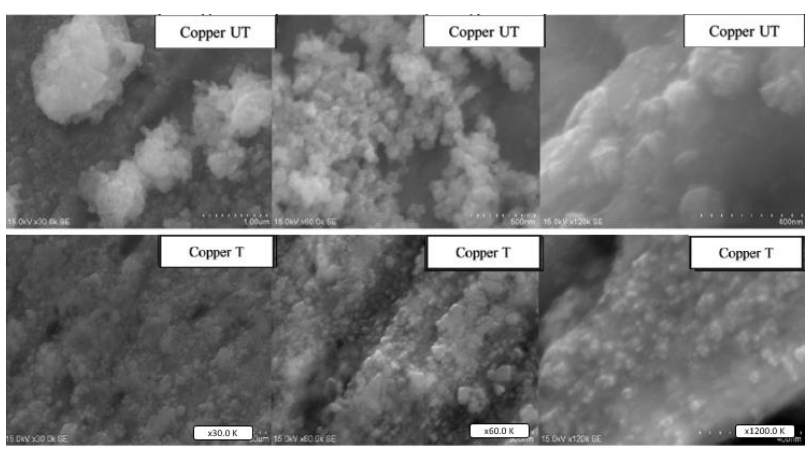

Fig 3 SEM image of treated and untreated Copper electrode [21] 


\subsection{Brass wire}

Brass wire had tendency of breakage under high tendency to break when exposed to heat. As sparks produces the heat, chances of breakage occurs. In order to improve its strength, they can be cryogenically treated to with stand high machining parameters. Researches proved that cryogenic treated wires perform more effective machined characteristics than pure brass wires. [23, 24, 25, 26, 29]. Figure (4) shows the SEM images that have been produces by jafferson [25]. Comparison images have been put on their paper for clear understanding of structural changes in the un-treated and treated wires. After Treated at $-1850 \mathrm{C}$ for $36 \mathrm{hrs}$ electrode had decreased with $58 \%$ in TWR, 55\% in MRR and increased with $18 \%$ in electric conductivity [25].

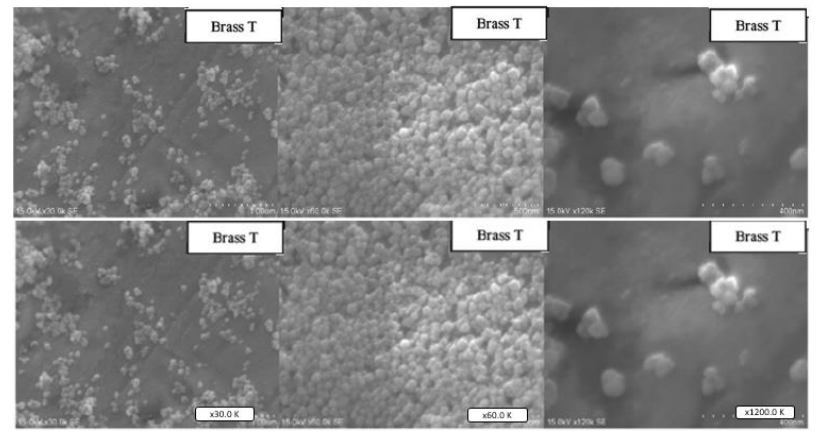

Fig 4 SEM image of treated and untreated brass electrode [21]

\subsection{Tungsten wire}

Tungsten wires are used for cutting hard-to-cut, aeronautical parts with high thick materials. [25] research was performed on WEDM using tungsten wire. The following SEM image [25] shows the structural changes compared treated and un-treated wire. From the SEM image (5), at 120k magnification, the grain size could be clearly shown stating that cryogenic treatment contracts the workpiece, there by reducing the empty cavity spaces.

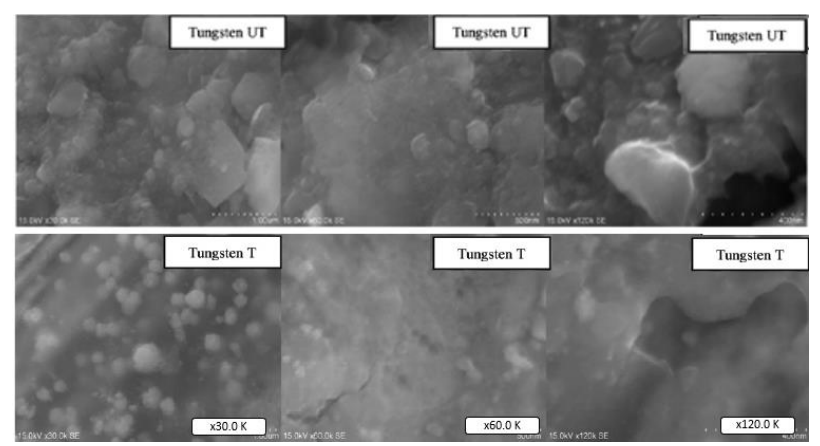

Fig-5 SEM image of treated and untreated tungsten electrode [21]

\section{Effect of cryogenic treated tool and workpiece in EDM process}

Electric discharge machining are adopted in duplicating the tool shape over the work pieces. In few cases they are used in drilling, cutting and tapping. In these process tool under goes reactive with the sparks and impurities in di-electric fluid. In order to retain tool without any changes, they are cryogenic treated to strength the structure and make it withstand the erosion with carbon atoms. Data et al [27] conducted EDM process with treated copper electrode in machining Inconel 825 in optimizing the residual stress and study the formation of while layer over the material. Same author [27] has participated in EDM process with cryogenic treated copper electrode and Inconel 825. Treatment was done with ramp down of $10 \mathrm{c} / \mathrm{min}$ from room temperature to $1850 \mathrm{c}$ and made it to hold up to $24 \mathrm{hrs}$ of duration. Then the materials were ramp up to room temperature with same $10 \mathrm{c} / \mathrm{min}$. Author could clearly state the magnifying view of carbon deposit over the electrode. In order to find out the tool wear, material removal rate and surface roughness [30] researches have been carried out and concluded by ANOVA that Ip is the factor that contributes in effect of MRR and tool wear rate. With validating mathematical model, the wear rate is formulated.

Ajay et al [23] conducted a comparative study over treated and untreated copper, brass and tungsten electrode in machining AISI d3 graded tool steel. With a clear graphical representation it was process that cryogenic tools could enrich the surface roughness. Cryogenic treatment was performed with ramp down from room temperature to $-184^{\circ} \mathrm{c}$ [34] a steady rate of $0.390 \mathrm{c} / \mathrm{min}$ and hold it for a span of $18 \mathrm{hrs}$. Materials were bought back to normal temperature with ramp up steady rate of $0.390 \mathrm{c} / \mathrm{min}$

\section{Effect of cryogenic treated tool and workpiece in WEDM process}

Hard-to-cut super alloys face the issues of wirebreakage, high surface integrity, and high temperature evolution. This partially shows its effect on the dimensional accuracy or re-machining process. In order to solve the problems that occur with metals like Inconel [28], titanium [29] and tungsten alloys [35] use of cryogenic treated wires electrodes are used practiced.

Tahir et al [26] has performed wire cut operation on HSLA steel in order to find the TWR, surface roughness and MRR. Through a ANOVA[33] representation author conclude that Ton contributed $64.34 \%$ on cutting speed and Toff of 15.83 in surface roughness. After treating the brass wire mechanical tests proved that $24.8 \%$ of electric conductivity has increased but $5.64 \%$ of decrease could be observed in tensile strength of brass.[c-10] experientally proved that wiretension doesnot effect the 
surface roughness. But cryogenic treated electrode improve it.

Saini et.al [24] made a comparison of treated and untreated zinc coated brass wire. Cryogenic treatment was done at ramp variation of $0.51 \mathrm{oC}$ and made the wire stand still at $-184 \mathrm{oC}$ for a span of $12 \mathrm{hrs}$. Authors could state that treated wire had good surface finish whereas Ton and wire tension were factors for surface roughness.

\section{Discussion and future scope.}

Cryogenic treatment improves the electrode (wire) in terms of conductivity, tool wear and material removal rates. Cryogenic treatment can be done without tempering the material with slow steady ramp-down and ramp-up process. Soaking the material for a long duration decreases the volume of the material there by leading to improper shape or surface. This is due to the shrinkage of the crystal structures which was studied to be at a rate of $12 \%$ on ramping for $24 \mathrm{hrs}$ at $-185 \mathrm{oc}$ at $10 \mathrm{c} / \mathrm{min}$ rate of ramping.

Aeronautical components are to be designed with high accuracy. In order to compete with production rate without consideration the cost of the product, productions have adopting additive manufacturing process. This leads in poor strength which can be proved in extreme condition. As a very low researchers have been conducted on the hard materials, the scope on solving issues of cutting precision materials can be participated.

Composite materials are designed to have high strength. Fiber metal matrix composites have poor conductivity.as composites are being replaced with super alloys, no researches have be conducted so far as of authors study.

\section{References}

1. Hong SY, J MANUF SCI E-T ASME 123(2), 331338. (2001),

2. Dix, M., Wertheim, R., Schmidt, G., \& Hochmuth, C., CIRP Annals, 63(1), 73-76.(2014)

3. Pušavec, F., Grguraš, D., Koch, M., \& Krajnik, P. CIRP Annals, 68(1), 73-76. (2019

4. Tummala Suresh Kumar, Kosaraju Satyanarayana, Materials Today: Proceeding, 26 (2), 3228-3233, (2020).

5. Tratton, P. F., Mater. Sci. Eng. A, 449, 809-812 (2007)

6. Jawahir, I. S., Attia, H., Biermann, D., Duflou, J., Klocke, F., Meyer, CIRP annals, 65(2), 713-736, (2016)

7. Ghosh, S., \& Rao, P. V. J. Clean. Prod. 231, 10361049. (2019)

8. He, Y., Chen, Q., Yang, S., Lu, C., Feng, M., Jiang, $\mathrm{Y} \&$ Liu, COMPOS PART A-APPL S, 108, 1222,(2018).

9. Senthilkumar, D., Rajendran, I., Pellizzari, M., \& Siiriainen, J, J. Mater. Process. Technol. 211(3), 396-401,(2011).
10. Datta, S., Biswal, B. B., \& Mahapatra, S. S., J. Manuf. Process. 26, 188-202 (2017).

11. Kumar, A., Kumar, V., \& Kumar, J. MACH SCI TECHNOL, 20(2), 201-230. (2016)

12. Tosun, N., \& Pihtili, H , INT J ADV MANUF TECH21(10-11), 857-865. (2003)

13. Bobbili, R., Madhu, V., \& Gogia, A. K., Int. J. Eng. Sci. Technol, 18(4), 720-726, (2015).

14. Thankachan, T., Soorya Prakash, K., \& Loganathan, M., Mater. Manuf. Process, 33(3), 350-358. (2018).

15. Maher, I., Sarhan, A. A., \& Hamdi, M. INT J ADV MANUF TECH 329-351, (2015).

16. Suresh Kumar Tummala, Dhasharatha G, E3S Web of Conferences 87, 01030 (2019)

17. Kruth, J. P., Lauwers, B., Schacht, B., \& Van Humbeeck, J. CIRP Annals, 53(1), 171-174. (2004).

18. Maher, I., Sarhan, A. A., \& Hamdi, M, INT J ADV MANUF TECH, 76(1-4), 329-351. (2015)

19. Jilani, S. T., \& Pandey, P. C. Int. J. Mach. Tools Manuf. 24(1), 31-43. (1984)

20. Ramarao, B. S. V., Sailesh, P., \& Sreenivasarao, M. Int. J. Sci. Eng. Technol. Res, 5(6), 2196-2203 (2016)

21. Rajyalakshmi, G., \& Ramaiah, P. V. ,INT J ADV MANUF TECH, 69(8), 1249-1262,(2013).

22. Kapoor, J., Khamba, J. S., \& Singh, S. Int. J. Mater. Eng. Innov,3(3-4), 190-203. (2012)

23. Sharma, A., Grover, N. K., \& Singh, A. Appl Mech Mater 813, 521-525 (2015).

24. SAINI, K. S., \& GARG, P. K. International journal medical and applied research, 9(1), 9-14. (2017).

25. Jafferson, J. M., \& Hariharan, P. Mater. Manuf. Process. 28(4), 397-402 (2013).

26. Suresh Kumar T, Sankar V, 2011 IEEE India Conference, INDICON, (2011)

27. Datta, S., \& Biswal, B. B. Measurement, 145, 611630 (2019)

28. Nayak, B. B., \& Mahapatra, S. S. Int. J. Eng. Sci. Technol. 19(1), 161-170. (2016).

29. Nandakumar, C., and A. R. Viswanadhan. Int. j. res. appl. sci. eng. technol. Technology 3, 23191163. (2014)

30. Singh, Neelesh, B. C. Routara, and R. K. Nayak, Materials Today, 5(11), 24277-24286, (2018)

31. Kosaraju, Satyanarayana, M. Vijay Kumar, and N. Sateesh. Material Today 5, 2 5343-5348. (2018)

32. Dhobe, M. M., Chopde, I. K., \& Gogte, C. L., Mater. Manuf. Process. 29(11-12), 1381-1386. (2014).

33. Satyanarayana, Kosaraju, Anne Venu Gopal, and Popuri Bangaru Babu., ijmmm. 13(2-3), 191-202. (2013).

34. Baloji, D., Anil, K., Satyanarayana, K., Singh, S. K., \& Naik, M. T. Material Today 18, 4475-4481. (2019)

35. Aggarwal, V., Khangura, S. S., \& Garg, R. K. INT J ADV MANUF TECH 79(1-4), 31-47. (2015). 